\title{
Increasing confidence in remote autobiographical memory and general knowledge: Extensions of the revelation effect
}

\author{
DANIEL M. BERNSTEIN and BRUCE W. A. WHITTLESEA \\ Simon Fraser University, Burnaby, British Columbia, Canada \\ and \\ ELIZABETH F. LOFTUS \\ University of Washington, Seattle, Washington
}

\begin{abstract}
In recognition tests, items presented in unusual ways (e.g., degraded, revealed in stages, or presented as anagrams) are often judged to be old more than are intact items. This revelation effect has been observed only in episodic judgments about the occurrence or frequency of relatively recent events. The present work extends the boundary conditions of this effect. In three experiments, subjects unscrambled anagrams in the context of answering questions about their childhood (e.g., broke a dwniwo playing ball) or while answering questions pertaining to world knowledge (e.g., fastest animal-elpraod). In each case, a revelation effect was observed: Solving an anagram increased confidence in remote autobiographical memories and in memory for world facts. These results contradict claims that the effect is an episodic memory phenomenon and challenge existing explanations of the revelation effect.
\end{abstract}

What makes an event seem like it was experienced in the past? For instance, how do we come to decide whether we got lost in a mall as a child, or broke a window, or were attacked by an animal? Whatever the process by which we make those judgments, we now know that current activities influence judgments about the past. For example, when people are asked to imagine that they had a particular experience, their confidence that they did have the experience increases. This occurs not only for events that probably did happen, but also for events that did not happen (e.g., Horselenberg et al., 2000). Reading stories or testimonials about events that probably did not happen increases confidence that the event did happen, no matter whether the event is plausible or implausible (Mazzoni, Loftus, \& Kirsch, 2001). Some of the manipulations that have produced these alterations in autobiography are rather heavy handed. For example, investigators might feed the subject false information, suggesting to the subject that their personal data imply a certain childhood history (e.g., your dreams mean that you were lost for an extended time; your fear profile means that you witnessed demonic possession; your excellent perceptual/motor skills mean that you stared at colorful mobiles in the days after birth). It is thought that these manipulations work by first making people believe that the suggested event is plausible and

D.M.B. gratefully acknowledges NIH support from a National Research Service Award. We thank Bill Hockley, Deanne Westerman, and an anonymous reviewer for helpful comments and suggestions. Correspondence should be addressed to D. M. Bernstein, Department of Psychology, University of Washington, P. O. Box 35152, Seattle, WA 98195 1525 (e-mail: db6@u.washington.edu). then that it was personally experienced. Whatever the precise mechanism, it is generally believed that at the time people are tested, they experience a greater sense of familiarity about the manipulated events, and this familiarity is misattributed to past experience. These manipulations are often quite elaborate and time consuming.

By contrast, a different group of researchers have found a simple manipulation that can distort judgments of the past. Briefly, subjects read words, and are later tested on their recognition memory. If the test item is scrambled, say dwniwo, and the subjects must first unscramble it (window), they are more likely to claim that the word occurred on the prior list. This is an example of what is now called the revelation effect. More generally, the revelation effect refers to the increased likelihood of a subject's reporting an item as old on a recognition test if it is presented in an unusual way (e.g., scrambled or slowly revealed; Luo, 1993; Peynircioğlu \& Tekcan, 1993; Watkins \& Peynircioğlu, 1990) or if it is preceded by an unrelated word that is presented in an unusual way (Westerman \& Greene, 1996, 1998).

Successful revelation effects have been limited to memory for relatively recent items, largely word-list items. Landau (2001) has demonstrated that the revelation effect increases over $24 \mathrm{~h}$. We wondered whether a revelation effect would occur when subjects answer questions about childhood experiences. If unscrambling window makes one more confident that it occurred on a recent word list, would unscrambling window in the event description broke a window playing ball make one more confident that one personally experienced this event as a child? We addressed this question in Experiment 1. More specifically, we gave subjects a list of event descriptions. For each event, the sub- 
jects had to report whether it had been personally experienced before the age of 10. Sample items included broke a window playing ball, witnessed a solar eclipse, got lost in a shopping mall for more than an hour. For half the items, a key word in the description had to be unscrambled before the judgment was made (e.g., witnessed a solar lecsiep).

\section{EXPERIMENT 1}

\section{Method}

Subjects. The subjects were 31 Simon Fraser University students. They received course credit for their participation and were tested individually.

Procedure. In the training phase, the subjects were taught to solve anagrams. They were shown 15 unconstrained phrases, such as went to the mountains, with one word of each phrase presented as an anagram (e.g., went to the umoanitsn). The anagrams were 4-10 letters long and could be unscrambled according to the following rules: $\{2,3,1,4\} ;\{2,3,1,5,4\} ;\{2,3,1,5,6,4\} ;\{2,3,1,5,7,4,6\} ;\{2,3,1,5,7$, $4,6,8\} ;\{2,3,1,5,7,4,6,9,8\} ;\{2,3,1,5,7,4,6,9,8,10\}$. For example, the " 2 " refers to the second letter in the anagram (e.g., the $f$ in aflt) that is the first letter in the unscrambled version of the target word, flat. Two anagrams of each length were presented in this phase, except that 7-letter items were shown on three trials. To simplify anagram solving, all solutions shared the same letter order for the first several letters (i.e., 2,3,1,5). The solution rules were given to the subject on paper and were available for consulting throughout the training and test phases of the experiment. The subjects were told that each different length of item had a different rule; they could identify the appropriate rule by counting the letters in the anagram. The 15 phrases were presented on paper in the same order for each subject. The subjects were asked to solve each anagram by typing its solution and then rating the likelihood that the event specified by the phrase occurred in their lives before the age of 10. This judgment was made using a scale from 1 (definitely did not occur before age 10) to 8 (definitely did occur before age 10).

The main test phase of the study used 52 new statements that were not presented during training. Thirty of these were taken from the Life Events Inventory (LEI) used by Garry, Manning, Loftus, and Sherman (1996), with some items altered slightly. At random, half of these phrases were shown intact; the remainder were presented with one word converted into an anagram. These anagram words were also from 4-10 letters long; the solutions to the anagram corresponded to the rules taught in the training phase. In addition, the phrases used in this test contained more contextual detail than did the training phrases, so that the subjects could conceivably guess the solution to an anagram without using the rule (e.g., won a blue brinbo [ribbon] at the fair). Intact and anagram versions of the phrases were presented in a random order, unique for each subject. On each trial, the subjects read the phrase, solved the anagram (if necessary), and then made a judgment about whether the event had occurred in their lives before the age of 10 , using the same 8-point scale.

\section{Results and Discussion}

For each subject, we calculated two numbers. First, we obtained the mean LEI rating for all intact items; that mean was $3.89(S E M=0.15)$ on the 8-point scale. Next, we obtained the mean LEI rating for all correctly unscrambled LEI items. The subjects correctly unscrambled $99 \%$ of the items, producing a mean rating of 4.17 (SEM = $0.13)$. These means were significantly different $[t(30)=$ $2.44, p<.05 ; S E M=0.113$ ]. Thus, by solving an anagram embedded within an event description, the subjects were led to greater confidence that the event had occurred in their childhood.

These results demonstrate that a revelation effect can occur for remote memories and not just for relatively recent events. Moreover, these findings extend the revelation effect to autobiographical memory. Although the effect is small (increased confidence of 0.28 on an 8-point scale $=3.5 \%$ ), it is impressive because it was produced by such a simple, quick manipulation. It might be informative to compare this effect size with those obtained using more elaborate procedures, such as imagination. For example, Manning (2000) induced some of his subjects to imagine that certain events had happened to them as children and asked them to write a description of their image. Imagination increased their belief that an event had happened by just under 0.4 units on the same 8-point scale used here, when either 1 day or 1 week had elapsed between imagination and testing. Thus, a manipulation that took Manning's subjects 4 min to complete per item produced changes in belief that were only slightly larger than the unscrambling manipulation that took our subjects a matter of seconds. Imagination has consistently been shown to enhance confidence that a childhood event occurred. This imagination inflation effect has been the subject of numerous investigations (e.g., Garry et al., 1996; Heaps \& Nash, 1999; Paddock et al., 1998). The usual explanation for imagination inflation is that the imagination activity increases the familiarity of the LEI item at test and that this familiarity is mistakenly attributed to childhood experience.

How does such an explanation map onto the present revelation result? What we do know is that we cannot assume in the present study that the subjects were experiencing increased familiarity that was mistakenly attributed. For example, the subjects in our study were clearly experiencing slightly increased confidence, but they could have been experiencing increased confidence about events that actually had happened to them. Perhaps they had broken a window playing ball, and the unscrambling made them more sure of this. However, the typical revelation effect has been shown repeatedly in studies involving wordlist recognition (where we know for sure which items are old and which are new). These studies demonstrate that unscrambling clearly makes novel items seem as if they had been experienced before.

Of course, it is risky to assume that we have increased belief in false childhood experiences simply by asking subjects to unscramble a key word in an event description. For this reason, we explore, in Experiment 2, whether unscrambling can increase belief not in personal facts from the past (the truth of which is unknown), but world facts from the past (the truth of which can be known). These world facts were general information items that would have been learned by the subjects in their remote past, and each could be categorized unambiguously as being true or false. Would unscrambling make the false facts seem true?

It is not obvious that the answer is yes. To date, all demonstrations of the revelation effect derive from tasks involving episodic memory judgments. For example, it occurs 
when subjects are asked to make recognition decisions about whether a target word had been studied previously (e.g., Watkins \& Peynircioğlu, 1990), and when subjects are asked to determine the precise study list on which a target word had been seen previously (Westerman \& Greene, 1996). Bornstein and Neely (2001) observed that the effect also occurs when subjects are asked to estimate situational frequency (e.g., how many times did you see the word BLANKET presented during training?). Although not literally a recognition task, this still involves memory for specific, recent episodes. In contrast, Watkins and Peynircioğlu (1990) obtained no revelation effect when subjects were asked to judge word frequency in everyday usage; they also failed to observe it in classification and lexical decision. Similarly, Frigo, Reas, and LeCompte (1999) failed to observe a revelation effect in a task involving judgments of personal relevance (does the word relate to you personally?). Experiment 2 was conducted in order to determine whether the revelation effect would extend to general knowledge.

\section{EXPERIMENT 2}

In this experiment, the subjects were shown general knowledge questions, together with true or false answers. The answers were either shown intact or as anagrams to be solved prior to making the true/false decision. So, for example, the subjects might be asked whether a particular animal is the fastest animal, and be given a true answer cheetah to respond to, or a plausible foil such as leopard. The proposed answers were sometimes intact and sometimes scrambled, as in elpraod.

\section{Method}

Subjects. The subjects were 32 Simon Fraser University students. They received course credit for their participation and were tested in groups ranging from 2 to 6 .

Materials and Procedure. Stimuli consisted of 128 general knowledge questions, 60 taken from Nelson and Narens (1980), the remaining 68 were created to be similar in the range of topics and the level of difficulty. A plausible foil was created for each of the questions (e.g., Fastest animal: true answer, cheetah; foil, leopard. Film director who made "The Godfather:" true answer, Coppola; foil, Scorcese). True answers were shown on half of the trials; half of the true answers and half of the false answers were intact, the remainder were anagrams. Each question appeared equally often with each of the four possible answer types (true intact, true anagram, false intact, false anagram) counterbalanced across subjects. Answers to all questions were five to eight letters long and could be un- scrambled according to the following rules: $\{4,2,3,5,1\} ;\{4,2,3,5,1,6\}$; $\{2,1,6,3,5,4,7\} ;\{2,1,6,3,5,4,7,8\}$. These rules were given to the subjects on paper and could be consulted at any time. The appropriate rule could be determined by counting the letters in the anagram.

All materials were presented on paper.

Prior to the test, the subjects were given instructions on how to solve the anagrams. On test trials containing anagrams, the subjects wrote their solutions beside the anagram. On each test trial, the subjects read the question, solved the anagram (if necessary), and then indicated whether the answer to the question was true or false by circling the item to indicate true and leaving it uncircled to indicate false. The subjects worked at their own pace.

\section{Results and Discussion}

For each subject, we examined how often four different types of items were called true. For anagram trials, we included only those that were successfully solved, which was $90 \%$ of all attempts. Table 1 lists the results of Experiments 2 and 3. Notice that for both the true and false answers, unscrambling led to an increase in the proportion claimed to be true.

A $2 \times 2$ analysis of variance (ANOVA) revealed a main effect of an answer's actual truth, which was not surprising $\left[F(1,31)=453.12, M S_{\mathrm{e}}=8.11\right]$. More importantly, a main effect for unscrambling also emerged. The subjects were more likely to claim an answer to be true when it was presented as an anagram $\left[F(1,31)=8.36, M S_{\mathrm{e}}=0.09\right]$. Simple effects indicated that the revelation effect was significant for true items $[t(31)=2.74 ; S E M=0.023]$ and marginally significant for false items $[t(31)=1.67, p=$ .055 , one-tailed; $S E M=0.027]$. The interaction was not significant $(F<1)$. Thus, importantly, we have shown that the revelation effect occurs for world facts from the subjects' past.

So why does unscrambling make both personal facts experienced in the distant past and world facts learned in the past seem to be more true? Does this finding have something to do with the fact that the subjects had to unscramble a word that was critical to their final judgment? For example, they unscrambled the anagram for leopard and then judged whether that very word, leopard, was or was not the fastest animal. Perhaps the unscrambling led to greater familiarity or activation of the critical word. We explored this possibility in Experiment 3, altering a procedure developed by prior investigators of the revelation effect (Westerman \& Greene, 1996, 1998). In Experiment 3, the subjects unscrambled a word that was entirely unrelated to the ultimate judgment that they would be required to make. For example, they unscrambled the word blender

Table 1

Probability of Claiming "True" for True and False Answers That Were Shown Intact or as Anagrams (Experiment 2) and for Answers That Were Shown Intact or Were Preceded by Anagrams (Experiment 3)

\begin{tabular}{|c|c|c|c|c|c|c|c|c|}
\hline \multirow[b]{3}{*}{ Experiment } & \multicolumn{4}{|c|}{ True } & \multicolumn{4}{|c|}{ False } \\
\hline & \multicolumn{2}{|c|}{ Intact } & \multicolumn{2}{|c|}{ Anagram } & \multicolumn{2}{|c|}{ Intact } & \multicolumn{2}{|c|}{ Anagram } \\
\hline & $M$ & $S E$ & $M$ & $S E$ & $M$ & $S E$ & $M$ & $S E$ \\
\hline 2 & .76 & .029 & .82 & .019 & .27 & .022 & .31 & .023 \\
\hline 3 & .79 & .015 & .83 & .019 & .30 & .025 & .32 & .027 \\
\hline
\end{tabular}


before judging whether a leopard was or was not the fastest animal. Would the subjects still be more likely to believe that the leopard was the fastest animal?

\section{EXPERIMENT 3}

\section{Method}

Subjects. The subjects were 33 Simon Fraser University students. They received course credit for their participation and were tested individually.

Materials and Procedure. Stimuli consisted of 112 general knowledge questions. To create the set, 40 questions were eliminated from the stock used in Experiment 2 and were replaced with 24 new questions. Items were eliminated because their answers were of uncommon spelling (e.g., Nairobi), or because the item had little effect in Experiment 1. For the anagrams, we used 56 eight-letter words with a frequency of $10-13$ per million (Kučera \& Francis, 1967). These words bore no relation to the answers to the trivia questions. They could all be unscrambled with the same rule: $\{3,7,2,4,1,6,5,8\}$.

Prior to the test, the subjects were shown how to use the rule to solve the anagrams. In the test, items were presented via computer. There were four conditions in the experiment, consisting of the factorial combination of anagram/no anagram and a true/false answer. Questions were randomly assigned to conditions and freshly randomized for each subject. On half the trials, answers were presented directly after each question. On the remaining trials, the question was shown, followed by an unrelated word presented as an anagram; the answer to the question (true or false) was not presented until the subject had finished solving the anagram. For example, the subjects could receive the question fastest animal followed by the unrelated anagram rteeanxl (external), followed by the false answer leopard in its intact form. Anagrams appeared on screen with the numbers $12345678 \mathrm{di}-$ rectly above the letters of the anagram (to help locate the order of letters), and the unscrambling rule (37241658) appeared directly beneath it. The subjects were told to unscramble the anagram as quickly as possible. They typed the solution using the keyboard, pressed the return key, and then received the answer to the trivia question. The question remained on screen throughout each trial until the subjects responded true or false, using a button box with the buttons appropriately labeled.

\section{Results and Discussion}

For each subject, we examined how often the four different item types were called true. As in Experiment 2, only correctly solved anagrams were analyzed. The subjects solved more than $95 \%$ of the anagrams. A $2 \times 2$ ANOVA revealed a main effect of an answer's actual truth, which was not surprising $\left[F(1,32)=370.79, M S_{\mathrm{e}}=8.17\right]$. More importantly, a main effect for unscrambling also emerged. The subjects were more likely to claim an answer to be true when it was preceded by an unrelated word presented as an anagram $\left[F(1,32)=4.78, M S_{\mathrm{e}}=0.04\right]$. Simple effects indicated that the revelation effect was significant for true items $[t(32)=2.69 ; S E M=0.016]$, but not for false items $[t(32)=0.93 ; S E M=0.025]$. The interaction was not significant $(F<1)$. Although the magnitude of the revelation effect obtained in the present experiment (3\%) appears to be smaller than that obtained in Experiment 2 $(5 \%)$, this difference was not reliable $[t(63)=0.878]$.

As in Experiment 2, our results show a revelation effect in a test of general knowledge, even when the unscrambling was performed on a word that was unconnected to the truth decision. This finding is analogous to previous recognition studies in which a revelation effect occurs for target words after unscrambling an unrelated word (Westerman \& Greene, 1996, 1998). Thus, the revelation effect for general knowledge is not due to elevated activation or familiarity of the critical item, because the critical item was not unscrambled. Familiarity-based explanations have been proffered to explain revelation effects when the anagram word is unrelated to the target word (Westerman, 2000). Other theories have also been proposed to explain such effects. According to one recent account, the revelation task temporarily displaces the study list context in working memory, causing subjects to adopt a more liberal recognition decision criterion (Niewiadomski \& Hockley, 2001). This criterion shift account and Westerman's familiarity-based explanation rely on global activation of a study list. As is evident in each of the present experiments, there was no study session; therefore, there was no list of words or related concepts that could be activated as a group. The revelation findings in all three of the present experiments must be due to something else. We pursue several possibilities next.

\section{GENERAL DISCUSSION}

To reiterate the main findings, we first showed that unscrambling a key word in an event description led subjects to claim more confidently that the event had occurred in their childhood (e.g., broke a dwniwo playing ball). Next we showed that by unscrambling a key word in a world fact, the subjects were led to claim that the fact was true, even when it was false (e.g., fastest animal-elpraod). In Experiment 3, we showed that by unscrambling an irrelevant word, the subjects were also led to believe that the world fact was true (e.g., fastest animal-rteeanxl-leopard).

These three studies extend the boundary conditions and challenge current explanations of the revelation effect by demonstrating that it is not, as formerly thought, an effect limited to decisions about particular, relatively recent events. Instead, revelation effects can also occur in reports of remote autobiographical memory and tests of general knowledge. Most accounts of the phenomenon point to increased or decreased activation of the target word or the set of words presented in training (Cameron \& Hockley, 2000; LeCompte, 1995; Luo, 1993; Niewiadomski \& Hockley, 2001; Westerman, 2000; Westerman \& Greene, 1998) or the activation of competing representations in memory (Hicks \& Marsh, 1998). Westerman and colleagues (Westerman, 2000; Westerman \& Greene, 1998) have suggested a cognitive leakage account that is based on global matching (cf. Gillund \& Shiffrin, 1984; Hintzman, 1988). This account specifies that words presented for recognition decisions activate the set of studied items. The amount of activation of each study-list word depends on its similarity to the current test item. The sum of activation across these study items determines the strength of the feeling of familiarity for each test word. Presentation of a word as an 
anagram causes similar activation of the study set, but acts more broadly: It activates representations of study words that are not activated by clear presentation of the test word itself. This activation persists at least until the target word is presented for recognition judgment, contributing to a feeling of familiarity for that item. This occurs whether the word presented as an anagram is the same word or a different word from the recognition target.

The critical aspect of this explanation for present purposes is that only members of the study set are thought to be activated in this way. This idea is necessary, given the assumption that familiarity results directly from activation of representations: Under this assumption, if words outside the study set were activated by test presentations, all test words would feel highly familiar, owing to their resemblance to masses of prior occurrences of themselves and other, similar words.

Hicks and Marsh (1998) have also proposed a familiaritybased account of the revelation effect. Unlike Westerman and Greene's (1998) account, this model posits that the revelation task activates competing alternative solutions in memory (e.g., the anagram dwniwo activates several potential words) that reduce the signal-to-noise ratio for the target word. Signal-to-noise ratio reductions increase the difficulty of the recognition decision. Subjects attempt to counter this increased difficulty by adopting a more liberal criterion.

Several lines of evidence argue against familiaritybased explanations of the revelation effect that rely on activation of either competing representations in memory or of the study list. Niewiadomski and Hockley (2001) asked subjects to solve either arithmetic problems or anagrams just prior to their making recognition judgments on unrelated words. According to familiarity/activation based explanations, a verbal revelation task (anagram) should produce a larger revelation effect than should an arithmetic task, because a verbal task is more likely to activate information relevant to memory for words on the study list. However, the authors observed revelation effects of similar magnitude in the arithmetic and anagram tasks. In contrast to Hicks and Marsh's (1998) familiarity-based criterion shift explanation, Niewiadomski and Hockley maintained that subjects adopt a more liberal decision criterion because the revelation task interrupts the study-list context in working memory. The latter explanation, however, is inconsistent with both the present results and with those of Frigo et al. (1999) in which a revelation effect occurred in the absence of a study list. Such findings challenge activation-based explanations of the revelation effect.

\section{A New Account of the Revelation Effect}

Whittlesea and Williams (1998) proposed that the feeling of familiarity is caused by a perception of discrepancy between two aspects of a processing experience. According to this notion, feelings of familiarity are not directly produced by the activation of a memory trace, but instead by people's evaluation of the quality of their performance, given what else is apparent to them about the circumstances under which they are operating. By this account, people chronically evaluate the coherence of their processing and experience subjective reactions when their performance departs from what they expect. True feelings of familiarity occur in recognition tests because the old words are facilitated by the earlier experience. At test, these words are processed with surprising ease, causing a perception of discrepancy; that perception is then unconsciously attributed to a prior experience, producing a conscious feeling of familiarity.

Illusions of familiarity arise by the same principles. For example, in encountering a novel stimulus presented in an unusual way, people sometimes experience a mismatch between their expectation of how fluently they ought to be able to process a given stimulus and the fluency with which they actually process that stimulus. When this mismatch is not appropriately attributed to the circumstances of test, it may instead be misattributed to past experience, causing an illusion of familiarity for a variety of materials and tasks (Whittlesea, 2002; Whittlesea \& Leboe, 2001; Whittlesea \& Williams, 1998, 2000, 2001a, 2001b). Whittlesea and Williams (2001b) have argued that the revelation effect arises for a similar reason. Upon encountering an anagram, subjects expect that it will be hard to solve. Consequently, successful or speedy anagram completion might be experienced as surprising. This perception of discrepancy is fallacious; solving an anagram easily should be used to revise the initial impression of difficulty. However, in the context of a recognition test, that perception of discrepancy might produce an illusion of familiarity.

This seems to be a likely explanation of Experiment 1 . In the training phase, because there was too little contextual support to guess the identity of the anagrams directly (e.g., went to the umoanitsn), the subjects could solve them only by using the rules. They would thus learn how difficult it was to solve the anagrams, creating a general expectation. However, in the test, solutions were made subtly easier by presenting more extensive context (e.g., broke a dwniwo playing ball). The subjects could thus sometimes solve the anagrams more easily than would be expected on the basis of the rule alone. If they did not realize the source of that ease, they could perceive it to be discrepant with their expectations, causing a false feeling of familiarity. ${ }^{1}$

However, the perception of discrepancy can occur in other ways as well. It is possible that the anagram task is experienced as somewhat difficult. That level of difficulty establishes a local standard against which subsequent processing is evaluated. When the target word is unscrambled in Experiment 2 or when the target word is presented intact after the unrelated anagram word in Experiment 3, subjects experience their reading of it as surprisingly fluent, causing a perception of discrepancy and feeling of familiarity. We suggest that this might be the origin of the biased truth claims in Experiments 2 and 3.

Another possible explanation for all three experiments is that the increase in endorsements following anagrams is due, in part, to repetition. Many investigators have shown 
that repetition increases plausibility ratings for general knowledge statements (Arkes, Hackett, \& Boehm, 1989; Bacon, 1979; Begg \& Armour, 1991; Bernstein, 2001; Hasher, Goldstein, \& Toppino, 1977). In the present studies, the act of solving the anagram, inserted between reading the question and judging the truth of the answer, or reading the life-event statement and judging its personal relevance, might be distracting; the anagram task might have caused the subjects to reread the statements before making their decision. On a second reading, the statement would be processed more fluently than on the first occasion. That facilitation might have caused the subjects to experience the statements as surprisingly coherent. In the context of knowledge or remembering judgments, that perception of discrepancy could cause an illusion of truth, or familiarity. It should be noted that repetition does not typically occur in the standard revelation procedure, in which the anagram task precedes the recognition decision on an unrelated target word. In such cases, repetition does not account for the revelation effect.

Whichever explanation of the revelation effect is eventually found to be correct, we suggest that accounts based on activation of members of the study list or competing representations in memory are not tenable. The present studies and those of Frigo et al. (1999) appear to demand an explanation in terms of evaluation and attribution. The false feeling of familiarity in the revelation effect is based on people's characterization of their performance, given those aspects of the situation that they find salient, and their inferences about the source of their performance under intuitive theories of cause and effect.

It is unclear why previous attempts to obtain the revelation effect in nonepisodic tests have failed. One possible reason is that relatively pallid judgments that do not demand much personal involvement have been used. In a standard recognition test, people know that the task is real: Half of the items were shown and half were not shown in training, and the subjects were challenged to discriminate between them. Under such conditions, we suspect that people do extensive evaluation of their processing in an attempt to discern the real answer. In that case, they might try to integrate various aspects of their processing; in the course of such integrative evaluation, they can become aware of a perception of discrepancy between parts of the experience. In contrast, judgments of word frequency in everyday language use and lexical decision (Watkins \& Peynircioğlu, 1990) and judgments of a word's personal relevance to the rater (Frigo et al., 1999) seem to be relatively abstract and pallid. We suspect that people do not perform such extensive evaluation of their performance in such cases, instead they respond on the basis of superficial characteristics of the stimuli, such as the ease of pronunciation. In so doing, they fail to experience a perception of discrepancy. It seems likely that judgments about one's remote autobiographicalmemory and about general world knowledge cause a revelation effect because people regard these judgments to be challenging, involving, and real, much like recognition tasks.

\section{REFERENCES}

Arkes, H. R., Hackett, C., \& Boenm, L. (1989). The generality of the relation between familiarity and judged validity. Journal of Behavioral Decision Making, 2, 81-94.

BACon, F. T. (1979). Credibility of repeated statements: Memory for trivia. Journal of Experimental Psychology: Human Learning \& Memory, 5, 241-252.

BegG, I., \& Armour, V. (1991). Repetition and the ring of truth. Canadian Journal of Behavioural Science, 23, 195-213.

Bernstein, D. M. (2001). Remembering and believing depend: A processing account. Unpublished doctoral dissertation, Simon Fraser University, Burnaby, BC.

Bornstein, B. H., \& Neely, C. B. (2001). The revelation effect in frequency judgment. Memory \& Cognition, 29, 209-213.

Cameron, T. E., \& Hockley, W. E. (2000). The revelation effect for item and associative recognition: Familiarity versus recollection. Memory \& Cognition, 28, 176-183.

Frigo, L. C., ReAs, D. L., \& LeCompte, D. C. (1999). Revelation without presentation: Counterfeit study list yields robust revelation effect. Memory \& Cognition, 27, 339-343.

Garry, M., Manning, C. G., Loftus, E. F., \& Sherman, S. J. (1996). Imagination inflation: Imagining a childhood event inflates confidence that it occurred. Psychonomic Bulletin \& Review, 3, 208-214.

Gillund, G., \& Shiffrin, R. M. (1984). A retrieval model for both recognition and recall. Psychological Review, 91, 1-67.

Hasher, L., Goldstein, D., \& Toppino, T. (1977). Frequency and the conference of referential validity. Journal of Verbal Learning \& Verbal Behavior, 16, 107-112.

HEAPS, C., \& NASH, M. (1999). Individual differences in imagination inflation. Psychonomic Bulletin \& Review, 6, 313-318.

Hicks, J. L., \& MARSH, R. L. (1998). A decrement-to-familiarity interpretation of the revelation effect from forced-choice tests of recognition memory. Journal of Experimental Psychology: Learning, Memory, \& Cognition, 24, 1105-1120.

Hintzman, D. L. (1988). Judgments of frequency and recognition memory in a multiple-trace memory model. Psychological Review, 95, 528-551.

Horselenberg, R., Merckelbach, H., Muris, P., Rassin, E., SijseNAAR, M., \& SPAAN, V. (2000). Imagining fictitious childhood events. Clinical Psychology \& Psychotherapy, 7, 128-137.

KuČERA, H., \& FrANCIS, W. N. (1967). Computationalanalysis of presentday American English. Providence, RI: Brown University Press.

LANDAU, J. D. (2001). Altering the balance of recollection and familiarity influences the revelation effect. American Journal of Psychology, 114, 425-437.

LeCompte, D.C. (1995). Recollective experience in the revelation effect: Separating the contributions of recollection and familiarity. Memory \& Cognition, 23, 324-334.

Luo, R. (1993). Enhanced feeling of recognition: Effect of identifying and manipulating test items on recognition memory. Journal of Experimental Psychology: Learning, Memory, \& Cognition, 19, 405-413.

MANNING, C. G. (2000). Imagination inflation with posttest delays: How long will it last? Unpublished doctoral dissertation, University of Washington, Seattle.

Mazzoni, G. A. L., Loftus, E. F., \& Kirsch, I. (2001). Changing beliefs about implausible autobiographical events: A little plausibility goes a long way. Journal of Experimental Psychology: Applied, 7, 5159.

Nelson, T. O., \& NARENS, L. (1980). Norms of 300 general-information questions: Accuracy of recall, latency of recall, and feeling-ofknowing ratings. Journal of Verbal Learning \& Verbal Behavior, 19, 338-368.

Niewiadomski, M. W., \& Hockley, W. E. (2001). Interrupting recognition memory: Tests of familiarity-based accounts of the revelation effect. Memory \& Cognition, 29, 1130-1138.

Paddock, J. R, Joseph, A. L., Chan, F. M., Terranova, S., Manning, C., \& LofTUs, E. F. (1998). When guided visualization procedures may backfire: Imagination inflation and predicting individual differences in suggestibility. Applied Cognitive Psychology, 12, S63-S75.

PeynircioĞlu, Z F., \& Tekcan, A. I. (1993). Revelation effect: Effort 
or priming does not create the sense of familiarity. Journal of Experimental Psychology: Learning, Memory, \& Cognition, 19, 382-388. Watkins, M. J., \& Peynircioğlu, Z F. (1990). The revelation effect: When disguising test items induces recognition. Journal of Experimental Psychology: Learning, Memory, \& Cognition, 16, 1012-1020.

Westerman, D. L. (2000). Recollection-based recognition eliminates the revelation effect in memory. Memory \& Cognition, 28, 167-175.

Westerman, D. L., \& Greene, R. L. (1996). On the generality of the revelation effect. Journal of Experimental Psychology: Learning, Memory, \& Cognition, 22, 1147-1153.

Westerman, D. L., \& Greene, R. L. (1998). The revelation that the revelation effect is not due to revelation. Journal of Experimental Psychology: Learning, Memory, \& Cognition, 24, 377-386.

Whitt lesea, B. W. A. (2002). False memory and the discrepancyattribution hypothesis: The prototype-familiarity illusion. Journal of Experimental Psychology: General, 131, 96-115.

Whittlesea, B. W. A., \& Leboe, J. (2001). Fluency-based versus discrepancy-based attributions: Evidence from classification and remembering. Manuscript submitted for publication.

Whittlesea, B. W. A., \& Williams, L. D. (1998). Why do strangers feel familiar, but friends don't? The unexpected basis of feelings of familiarity. Acta Psychologica, 98, 141-166.

Whittlesea, B. W. A., \& Williams, L. D. (2000). The source of feel- ings of familiarity: The discrepancy-attribution hypothesis. Journal of Experimental Psychology: Learning, Memory, \& Cognition, 26, 547565.

Whittlesea, B. W. A., \& Williams, L. D. (2001a). The discrepancyattribution hypothesis: I. The heuristic basis of feelings of familiarity. Journal of Experimental Psychology: Learning, Memory, \& Cognition, 27, 3-13.

Whittlesea, B. W. A., \& Williams, L. D. (2001b). The discrepancyattribution hypothesis: II. Expectation, uncertainty, surprise, and feelings of familiarity. Journal of Experimental Psychology: Learning, Memory, \& Cognition, 27, 14-33.

\section{NOTE}

1. This explanation suggests an additional study in which subjects receive no training on anagrams and no anagram solutions. Such a procedure should force subjects to rely exclusively on the contextual detail of each sentence. Consequently, they should experience little to no surprise when they successfully unscramble the anagram, thereby reducing or eliminating the revelation effect. When we ran this study, we failed to obtain a revelation effect $[t(24)=1.20, p>.2]$, lending further support to our claim that discrepancy plays an important role in the revelation effect observed in Experiment 1.

(Manuscript received August 2, 2001;

revision accepted for publication December 17, 2001.) 